\title{
EDITORIAL
}

\section{Respiratory syncytial virus: a sleeping giant?}

\author{
D.M. Fleming and A.J. Elliot
}

$\mathbf{T}$ he study by JANSEN et al. [1] in the present issue of the European Respiratory Journal focuses on the impact of influenza and respiratory syncytial virus (RSV) on mortality and hospital admissions. As in many other similar publications, it emphasises the significance of RSV (and influenza) in all age groups and not just children, in whom the impact is already well recognised [1]. In common with other similar studies, the evidence presented is derived by linking independent data on virus circulation (mainly from specimens sampled in children) with data on healthcare utilisation. As such, it falls short of direct linkage between cause and effect, although this has been demonstrated in experimental studies, which have included wild-type virus in addition to low temperature attenuated strains. In one of these studies, McKAY et al. [2] administered wild-type virus to 20 human volunteers, and nine of them developed upper respiratory tract symptoms.

In community-based observational cohort studies between 1977 and 1981, MONTO and SulLIVAN [3] demonstrated average RSV isolation rates of 56 per 100 person-yrs in children aged 0-4 yrs, seven in those aged 5-19 yrs and somewhat less in older people. RSV demonstrated a clearer seasonality than other viruses studied. ZAMBON et al. [4] identified RSV in nose/throat virology specimens from community-based persons of all ages with influenza-like illness. Several studies have shown high rates of laboratory-confirmed infection in older people and especially in persons with chronic respiratory disease [5, 6]. Basing their findings on serological studies, DOWELL et al. [5] considered RSV to be one of the four most common pathogens identified in cases of lower respiratory tract infection in hospitalised adults, but went on to comment that none of the 57 cases of RSV infection included in the study were diagnosed during their period of hospitalisation. In an excellent recent review of RSV infection in adults, FALSEY [7] described RSV as a predictable cause of yearly epidemics of respiratory illness in temperate climates and drew attention to the clustering of cases in the staff and patients of a nursing home, which pointed to nosocomial spread. The impact of RSV infection in nursing homes has been recognised in several publications [8-10].

In data obtained in the Weekly Returns Service of the Royal College of General Practitioners (Birmingham, UK) [11], ELLIOT et al. [12] have shown that the clinical incidence of acute

Birmingham Research Unit of the Royal College of General Practitioners, Birmingham, UK.

STATEMENT OF INTEREST: None declared.

CORRESPONDENCE: D.M. Fleming, Birmingham Research Unit of the Royal College of General Practitioners, Lordswood House, 54 Lordswood Road, Harborne, Birmingham, B17 9DB, UK. Fax: 44 1214282084.E-mail: dfleming@rcgpbhamresunit.nhs.uk bronchitis in the elderly peaks $\sim 3$ weeks later than that in children, unlike the incidence of influenza-like illness, which peaks in all age groups at the same time. Acute bronchitis diagnosed in children in the community coincides with the period of RSV reports to the Health Protection Agency mainly from hospitalised children; however, no comparable data are available from a sufficient number of adults. This finding influences the interpretation of clinical incidence data of both influenza and acute bronchitis. Since RSV precedes the appearance of influenza in most winters, the impact of RSV is sometimes lost in that attributable to influenza and tends to inflate the latter [13].

Notwithstanding the increasing evidence of the pathogenicity of RSV, why is it that the impact of this virus is so widely under-recognised? Why is it that the World Health Organization gives such a high priority to influenza but considers RSV an illness of little importance?

\section{PERCEPTIONS OF ILLNESS}

Common acute respiratory illnesses are minor in their impact in the majority of persons who become infected. "It is only a cold" or "It is a virus infection" reflect attitudes, even among the medical profession, that are only dislodged after repeated publications of research work demonstrating sufficient persons with serious manifestations of apparently "minor infections" which, together, constitute a large public health problem. A small study of RSV infections in hospital employees showed an average absence from work of 6 days [14]; a later study reported an average of 9.5 days in 211 healthy working adults [15]. In comparison, sickness absence due to influenza has been estimated at $\sim 3$ days per case [16]. It would appear, therefore, that RSV-related disease has a greater economic impact than influenza in relation to days lost from work; perhaps data on economic impact speak louder than data on disease incidence.

Perceptions of illness reinforce decision behaviour. As a result, paediatricians caring for babies with acute respiratory infections routinely look for RSV, whereas at the opposite end of the age spectrum, doctors caring for the elderly are more likely to investigate for influenza. Is the evidence now not sufficient enough that, in cases of acute infection prompting investigation, both these pathogens should be sought as routine and not simply one or the other? Perhaps an emphasis on influenza surveillance should be replaced by a much broader surveillance of acute respiratory infections? That is not to argue for routine diagnostic investigation, which can never be justified on economic grounds, but for structured respiratory disease surveillance in dedicated networks.

Perceptions of illness often steer us along particular pathways. The impetus for case definition in disease surveillance has laid 
such a strong emphasis on elevated temperature as an important criterion for diagnosing influenza that the absence of a raised temperature reduces the likelihood of virological investigation. RSV infection in adults and the elderly is not particularly associated with a raised temperature and afebrile persons are less likely to be investigated in surveillance networks concentrating specifically on the diagnosis of influenza.

The similarity of timing of the clinical presentation of persons with respiratory disease, whether symptomatically more focussed on upper or lower respiratory tracts, demonstrates that most common respiratory pathogens have the potential to cause widely diverse upper and lower symptoms, making it very difficult to discriminate between them. Both influenza and RSV infections are associated with increased numbers of persons presenting to general practitioners with a variety of respiratory syndromes, including acute bronchitis, common cold and otitis media [13]. Nevertheless, there are some pointers towards the diagnosis of RSV infection, such as wheeze, which has been commonly reported as more prominent in RSV than in influenza $[5,6]$. Studies of exacerbation of chronic bronchitis often concentrate on the appropriateness of antibiotic use but comparatively few have seriously looked at possible virological causes and, in particular, RSV, for which antibiotics are probably irrelevant.

\section{CASE PRESENTATION}

In observational studies in the community, RSV is commonly identified as an important pathogen. However, routine studies of persons presenting to doctors do not do so to the same extent. Part of this reason lies in late presentation of most older persons when suffering from acute respiratory illnesses. Ross et al. [17] observed that whilst $80 \%$ of children aged $0-4$ yrs presented within $48 \mathrm{~h}$ of symptom onset of influenza-like illness, only $19 \%$ of persons aged $>65$ yrs did. Older persons frequently present because their cough is not getting better, and well past the critical initial period of maximum viral replication during which the respiratory epithelial lining is damaged. Virus shedding of influenza reduces sharply after the third day of illness [18] but much less is known about the natural history of virus shedding in RSV infection [19].

\section{DIAGNOSIS}

If RSV is to achieve a higher profile, more confirmed clinical cases need to be recognised, and, ideally, be confirmed from routine clinical practice in the community and in hospitals. However, there are many issues surrounding accurate diagnosis. Firstly, the preferred swab specimen, a specimen for viral culture, is not a realistic option in most community circumstances because the virus is highly labile and does not survive routine transport methods. The best specimen site has not been established, although there seems to be a consensus around the use of a nose/throat swab obtained from "vigorous swabbing". Nasal washes may be better but are much less acceptable. Sensitivity has been much improved by the use of RT-PCR tests, although these are expensive and labour intensive and are not widely used [7]. There is a tradition of investigating patients with acute exacerbations of bronchitis predominantly for bacteria, but specimens obtained for sputum culture could be used for PCR investigation [7]. There are a number of near patient tests currently available for
RSV with sufficient sensitivity and specificity to encourage their routine use (especially if coupled with investigation of influenza) in selected situations [20, 21]. For example, when contemplating admission of a patient with acute respiratory infection, a positive RSV and negative influenza result would favour admission if respiratory symptoms are severe, whereas a negative RSV and a positive influenza result may, in some circumstances, prompt appropriate antiviral treatment and avoid admission [22].

\section{TREATMENT AND PREVENTION}

There are no specific treatments for respiratory syncytial virus infection, and prevention using monoclonal antibodies is only indicated for premature infants [23, 24]. However, the absence of treatment is perhaps the main reason why respiratory syncytial virus is not actively sought when persons present with acute respiratory infection. Many attempts have been made to establish a safe respiratory syncytial virus vaccine but these seem perpetually like the mirage over the horizon. A chicken and egg situation exists. Further developments on both prevention and treatment will follow a clearer and unequivocal understanding of the impact of respiratory syncytial virus infection; however, routine budgets are unlikely to fund the investigation of an organism for which there is no treatment. Continuing research is needed to quantify the contribution of respiratory syncytial virus to respiratory infection and to clarify its role as a major factor in the aetiology of asthma [25]. Routine virological studies in influenza surveillance networks carry this work forward, but the methodologies and case sampling procedures have been developed around influenza, and may not be ideal for the detection of respiratory syncytial virus [4, 26, 27]. Even if respiratory syncytial virus is not universally accepted as a priority illness, the uncertainty surrounding the impact of respiratory syncytial virus is a serious problem that calls for prompt resolution. Priorities for research include: improved information on virus shedding in naturally occurring respiratory infections in persons of all ages; further studies of disease impact in terms of sickness absence and time to recovery; and the investigation of the relative impact of differing virus subtypes and of simultaneous infection with more than one respiratory virus $[4,26,28]$.

\section{REFERENCES}

1 Jansen AGSC, Sanders EAM, Hoes AW, van Loon AM, Hak E. Influenza- and respiratory syncytial virus-associated mortality and hospitalisations. Eur Respir J 2007; 30: 1158-1166.

2 McKay E, Higgins P, Tyrrell D, Pringle C. Immunogenicity and pathogenicity of temperature-sensitive modified respiratory syncytial virus in adult volunteers. J Med Virol 1988; 25: 411-421.

3 Monto AS, Sullivan KM. Acute respiratory illness in the community. Frequency of illness and the agents involved. Epidemiol Infect 1993; 110: 145-160.

4 Zambon MC, Stockton JD, Clewley JP, Fleming DM. Contribution of influenza and respiratory syncytial virus to community cases of influenza-like illness: an observational study. Lancet 2001; 358: 1410-1416. 
5 Dowell SF, Anderson LJ, Gary HE Jr, et al. Respiratory syncytial virus is an important cause of communityacquired lower respiratory infection among hospitalized adults. J Infect Dis 1996; 174: 456-462.

6 Falsey AR, Cunningham CK, Barker WH, et al. Respiratory syncytial virus and influenza A infections in the hospitalized elderly. J Infect Dis 1995; 172: 389-394.

7 Falsey AR. Respiratory syncytial virus infection in adults. Semin Respir Crit Care Med 2007; 28: 171-181.

8 Falsey AR, McCann RM, Hall WJ, et al. Acute respiratory tract infection in daycare centers for older persons. J Am Geriatr Soc 1995; 43: 30-36.

9 Falsey AR, Treanor JJ, Betts RF, Walsh EE. Viral respiratory infections in the institutionalized elderly: clinical and epidemiologic findings. J Am Geriatr Soc 1992; 40: 115-119.

10 Nicholson KG, Baker DJ, Farquhar A, Hurd D, Kent J, Smith SH. Acute upper respiratory tract viral illness and influenza immunization in homes for the elderly. Epidemiol Infect 1990; 105: 609-618.

11 Birmingham Research Unit of the Royal College of General Practitioners. Weekly Returns Service Annual Report 2006. www.rcgp.org.uk/continuing_the_gp_journey/bru/annual_ reports. Date last updated: September 10, 2007. Date last accessed: September 10, 2007.

12 Elliot AJ, Cross KW, Smith GE, Fleming DM. Do children drive the spread of influenza-like illness in the community? (Abstract P124). In: Options for the Control of Influenza VI. Toronto, MediTech Media Conferencing Inc., 2007; p. 91.

13 Fleming DM, Elliot AJ, Cross KW. Morbidity profiles of patients consulting during influenza and respiratory syncytial virus active periods. Epidemiol Infect 2007; 135: 1099-1108.

14 Hall WJ, Hall CB, Speers DM. Respiratory syncytial virus infection in adults: clinical, virologic, and serial pulmonary function studies. Ann Intern Med 1978; 88: 203-205.

15 Hall CB, Long CE, Schnabel KC. Respiratory syncytial virus infections in previously healthy working adults. Clin Infect Dis 2001; 33: 792-796.

16 Aoki FY, Fleming DM, Griffin AD, Lacey LA, Edmundson S. Impact of zanamivir treatment on productivity, health status and healthcare resource use in patients with influenza. Zanamivir Study Group. Pharmacoeconomics 2000; 17: 187-195.

17 Ross AM, Kai J, Salter R, Ross J, Fleming DM. Presentation with influenza-like illness in general practice: implications for use of neuraminidase inhibitors. Commun Dis Public Health 2000; 3: 256-260.

18 Gentile D, Doyle W, Whiteside T, Fireman P, Hayden FG, Skoner D. Increased interleukin-6 levels in nasal lavage samples following experimental influenza A virus infection. Clin Diagn Lab Immunol 1998; 5: 604-608.

19 Falsey AR, Formica MA, Treanor JJ, Walsh EE. Comparison of quantitative reverse transcription-PCR to viral culture for assessment of respiratory syncytial virus shedding. J Clin Microbiol 2003; 41: 4160-4165.

20 Zheng X, Quianzon S, Mu Y, Katz BZ. Comparison of two new rapid antigen detection assays for respiratory syncytial virus with another assay and shell vial culture. J Clin Virol 2004; 31: 130-133.

21 Slinger R, Milk R, Gaboury I, Diaz-Mitoma F. Evaluation of the QuickLab RSV test, a new rapid lateral-flow immunoassay for detection of respiratory syncytial virus antigen. J Clin Microbiol 2004; 42: 3731-3733.

22 Democratis J, McNally T, Nicholson KG, Stephenson I. The impact of rapid antigen testing for influenza on paediatric hospital admissions in a large UK emergency department: a retrospective observation (Abstract P1310). In: Options for the Control of Influenza VI. Toronto, MediTech Media Conferencing Inc., 2007; p. 279.

23 Pedraz C, Carbonell-Estrany X, Figueras-Aloy J, Quero J. Effect of palivizumab prophylaxis in decreasing respiratory syncytial virus hospitalizations in premature infants. Pediatr Infect Dis J 2003; 22: 823-827.

24 The Impact-RSV Study Group. Palivizumab, a humanized respiratory syncytial virus monoclonal antibody, reduces hospitalization from respiratory syncytial virus infection in high-risk infants. Pediatrics 1998; 102: 531-537.

25 Message SD, Johnston SL. Viruses in asthma. Br Med Bull 2002; 61: 29-43.

26 Lina B, Valette M, Foray S, et al. Surveillance of community-acquired viral infections due to respiratory viruses in Rhone-Alpes (France) during winter 1994 to 1995. J Clin Microbiol 1996; 34: 3007-3011.

27 Meerhoff TJ, Fleming D, Smith A, et al. Surveillance recommendations based on an exploratory analysis of respiratory syncytial virus reports derived from the European Influenza Surveillance System. BMC Infect Dis 2006; 6: 128.

28 Drews AL, Atmar RL, Glezen WP, Baxter BD, Piedra PA, Greenberg SB. Dual respiratory virus infections. Clin Infect Dis 1997; 25: 1421-1429. 